\title{
Defects in the hydro-insulation of the underground part of the building of Tovstonogov Bolshoi Drama Theater after the reconstruction
}

\author{
Antonina Yudina ${ }^{1, *}$ \\ ${ }^{1}$ Saint Petersburg State University of Architecture and Civil Engineering, Saint Petersburg, Russia
}

\begin{abstract}
The paper presents the study of defects in the hydro-insulation of the underground part of the BDT building ("The Russian State Bolshoi Drama Theater named after Tovstonogov G.A.") after the reconstruction. Within the reconstruction of such buildings, work is often performed to deepen the floor below the existing level of the foundation to create the additional area. During excavation works for deepening, demolition of the old concrete floors and after arrangement of a new floor slab in the basement, as a result of poorly executed hydro-insulation works, capillary moisture is raised along the body of the wall. As a result, wall structures are in conditions of high humidity, which leads to their gradual destruction.
\end{abstract}

\section{Introduction}

When reconstructing the underground part of old buildings, for example, when deepening the basement, work is carried out to strengthen the foundations and hydro-insulation. Foundations in such buildings are usually rubble tape, less often rubble-concrete or brick using lime, cement and complex mortars. Wherein, they have a fairly high indicator of the density of the foundations (the ratio of the area of the sole of the foundations to the construction area), which reaches about $40 \%$. In most cases, with such a high rate of foundation strength, $50 \%$ of the standard pressure is not used, which makes it possible to increase the pressure on the base during reconstruction of buildings.

One of the actual issues in the reconstruction of buildings is the provision of hydroinsulation of building structures of the underground part. An effective system of protection against moisture is determined only after identifying the source of the moisture, establishing the nature of the interaction of the structure with the environment and the degree of preservation of the finishing materials.

The source of humidification is usually water acting on the structure. This can be filtration water, water arising from rain, thawed and accidental waters, groundwater held in the ground by adhesive and capillary forces and groundwater, depending on the level of groundwater depending on the terrain and the position of the water-resistant layer. The impact of these waters may not exert hydrostatic pressure on the structure if the design

\footnotetext{
*Corresponding author: yudinaantonina2017@mail.ru
} 
solution provides unhindered outflow of water without the formation of stagnant zones. The influence of these waters may not exert hydrostatic pressure on the structure if the design solution provides unhindered outflow of water without the formation of stagnant zones.

To identify defects in hydro-insulation after reconstruction of the underground part of buildings when the basement is buried and structures become wet, it is necessary to conduct a survey, and to develop technological solutions to eliminate them based on the results of the survey [1-13].

\section{Methods}

In the process of studying defects in hydro-insulation of the underground part of the BDT building ("The Russian State Bolshoi Drama Theater named after Tovstonogov G.A."), a petrographic study of control core materials and mortar materials for hydro-insulating coating of basement walls in the areas of anticapillary cut-offs was performed.

Petrographic study of solutions under an MBS-10 microscope using simple chemical reactions to assess the composition of binders (the presence of calcium carbonate, sulfates, signs of the Portland cement presence, the presence of $\mathrm{Ca}(\mathrm{OH})_{2}$ and aqueous calcium aluminosilicates) with the following reagents: $5 \% \mathrm{HCl}$ solution, $\mathrm{BaCl}_{2}$ solution, distilled water and a solution of phenolphthalein in alcohol.

The moisture content of the material was evaluated by a moisture meter.

In the process of observations, the relative weight, hardness and density of solutions, porosity in the observation plane, composition and amount of binder and filler, the presence of modifying additives in general, fibrous materials were evaluated.

\section{Results and discussion}

When reconstructing old buildings, the most critical are the hydro-insulation works of the underground part of the building. As a rule, the most common problems arise when performing work to deepen a basement. As a result of a violation of the hydro-insulation technology, soaking of building structures occurs and, as a result, defects (peeling of the paint, wetting of the stucco layer on the walls, cracks in the brickwork of the basement walls, efflorescences, etc.), as well as defects that potentially reduce the strength and water resistance of load-bearing and enclosing structures associated with capillary rising of moisture along the wall as a result of violation, absence or poor-quality performance of shut-off anti-capillary hydro-insulation.

In the spring, the groundwater level rises and interacting with mineral and organic particles, the water in its chemical composition can be, for example, sulfate, carbon dioxide, etc., which leads to leaching of lime in concrete structures. Rain water, taking from the atmosphere a large amount of gaseous industrial emissions (carbon oxides, sulfur, nitrogen, phosphorus, etc.) turns into an acid solution, which also contributes to the destruction of concrete, brick, etc.

A visual and instrumental study of the basement of the Bolshoi Drama Theater ("The Russian State Bolshoi Drama Theater named after Tovstonogov G.A."), for assessing the quality of the hydro-insulation work performed during the reconstruction of the basement, revealed numerous signs of leaks on the surfaces of walls, floors and various damage to them in the form of cracks. Defects were discovered, most of which are associated with soaking and a number of defects that potentially reduce the strength and waterproofness of load-bearing and enclosing structures that are dispersed throughout the basement.

A significant part of the defects is associated with the capillary rise of moisture along the body of the wall as a result of violation, absence or poor quality of cut-off anti-capillary 
hydro-insulation: cracks in the basement wall structures with opening widths from 0.5 to 5 $\mathrm{mm}$; cracks in the basement ceiling structures with an opening width of 0.5 to $1 \mathrm{~mm}$; wetting of the walls, floor and ceiling of the basement; the formation of mold and fungus on the walls of the basement; peeling of ceramic tiles from the walls and floor of the basement, etc.

A small number of cracks were found in the brickwork of the basement walls (crack opening width is $1-2 \mathrm{~mm}$ ). The nature of the cracks in the masonry indicates their sedimentary and power origin.

These defects and damages are defined as significant and removable defects - defects that significantly affect the intended use of the product and its durability, the elimination of which is technically possible and advisable.

According to the results of a visual examination, the condition of the hydro-insulation of the basement of the main building of the Bolshoi Drama Theater named after Tovstonogov in accordance with GOST 31937-2011 can be described as limitedfunctioning, and in accordance with SP 13-102-2003, as unacceptable.

A petrographic study of the brickwork materials of the BDT basement was carried out by drilling pits in the basement walls and then studying the materials of control cores and mortar hydro-insulating coatings of the basement walls in the areas of the anti-capillary cutouts. According to the results of the study, it was found that: in the studied masonry cores, there are no signs of the presence of foreign materials that could be mistaken for products of reinforcing hydrophobic injection; in plastering vertical surfaces of basement walls, the presence of sanitizing solutions with a small proportion of hydrophobicity is observed in one sample only (Fig. 1, 2).

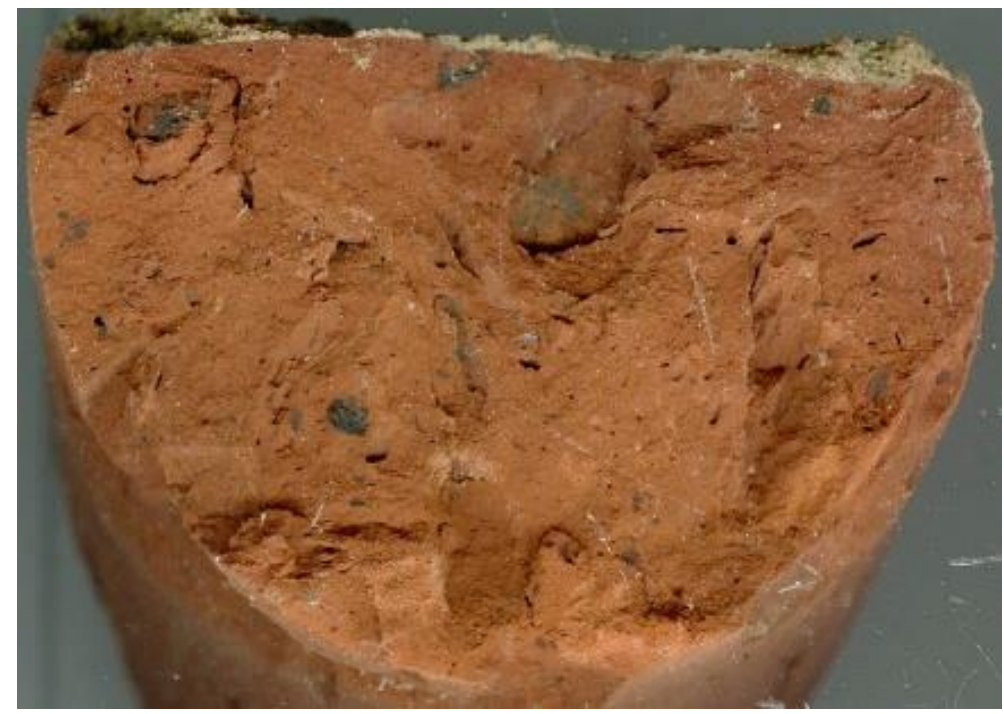

Fig. 1. Sample No.1 - no extraneous material along the pores, cavities and cracks. 


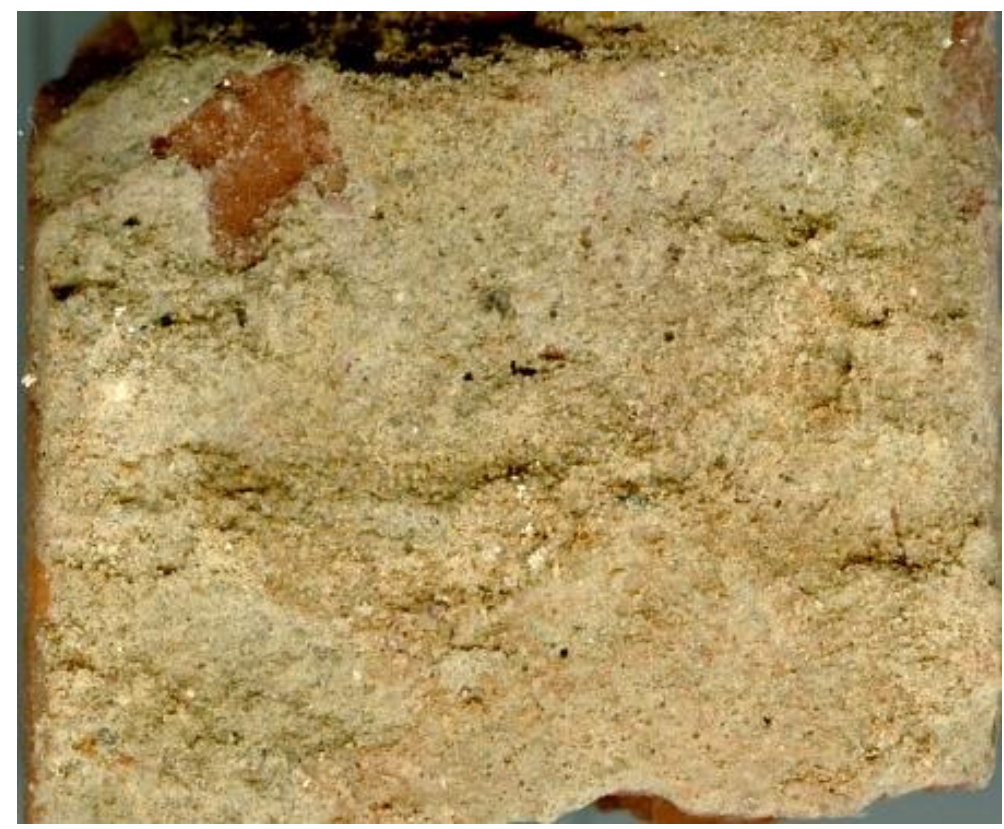

Fig. 2. Sample No.2 (coating on the wall surface) - there is a decrease in wettability and the presence of a significant amount of a synthetic modifier that determines the increased hydrophobicity of rasters.

Thus, it is necessary to state that in the studied masonry cores of the brickwork there are no signs of the presence of foreign materials that could be mistaken for products of reinforcing and / or hydrophobic injection.

The hydro-insulation works included an anti-capillary cut-off device arrangement that prevented water from rising through the brickwork of the foundation by injection with Ceresit 081 or Oxal HSL using boreholes, followed by treating vertical and horizontal surfaces with ceresitic plaster.

Brief description of the technology of the horizontal anti-capillary cut-off device: boreholes are drilled at an angle of $15-30^{\circ}$ to the horizontal plane and are arranged in increments of 150-250 $\mathrm{mm}$ (the smaller the pitch, the better the impregnation), but not more than $400 \mathrm{~mm}$, then injection packer needles are installed, with the help of pumps the insulating composition is pumped inside, at the end of the work, the packers are cut off and repaired with the repair mixture. The counter-capillary horizontal cut-off - by injecting the brickwork with the cerresit mortar through the boreholes drilled in the walls of the basement followed by coating the walls with waterproofing plaster. The conducted studies did not confirm the fact of the implementation of these works.

\section{Conclusion}

A visual and instrumental study of the basement of the Bolshoi Drama Theater ("The Russian State Bolshoi Drama Theater named after GA Tovstonogov"), for the purpose of assessing the quality of the hydro-insulation works performed during the reconstruction of the basement, revealed numerous defects in the form of leaks on the surface of the walls, various damage to them in the form of cracks, etc. A petrographic study of the brickwork materials of the BDT basement revealed a complete absence of reinforcing hydrophobic injection, i.e., anti-capillary cut-offs were practically not carried out, which explains the presence of moisture in the basement, namely the presence of leaks and moisture in the 
basement walls, efflorescence, delamination of the plaster and paint, destruction (swelling) of the tiled floor and walls in almost all basements.

\section{References}

1. SN RK 3.02-36-2006. Construction norms for designing hydro-insulation of underground parts of buildings and structures (2006)

2. TSN 50-302-2004. Designing the foundations of buildings and structures in St. Petersburg: Government of St. Petersburg, p.58 (2004)

3. The technological regulations for the design and implementation of hydro-insulation and corrosion protection works of monolithic and prefabricated concrete and reinforced concrete structures. 2nd ed., Revised. And add., SRO "RSPPPG", Moscow (2008)

4. G.N. Savilova, Construction Materials, No. 7, 32-34

5. L.P. Zarubina, Hydro-insulation of buildings and structures (BHV, St. Petersburg, 2011)

6. A.I. Bedov, V.F. Saprykin, Survey and reconstruction of reinforced concrete and stone structures of operated buildings and structures (p. 190, ASV, Moscow, 1995)

7. J. Dai, Y. Akira, et al., Cement and Concrete Composites, 32(2), 101-109 (2010) doi:10.1016/j.cemconcomp.2009.11.001

8. Y. Ohama, Construction and Building Materials, 10(1 SPEC. ISS.), 77-82 (1996) doi:10.1016/0950-0618(95)00063-1

9. S. Agarwal, N. Snavely, et al., Proceedings of the IEEE International Conference on Computer Vision, 72-79 (2009) doi:10.1109/ICCV.2009.5459148

10. B. Curless, M. Levoy, Proceedings of the ACM SIGGRAPH Conference on Computer Graphics, 303-312 (1996)

11. A. Dereeper, V. Guignon, et al., Nucleic Acids Research, 36 (Web Server issue), W465-469 (2008) doi:10.1093/nar/gkn 180

12. J.F. Dewey, Pitman III, W. C. Ryan, et al., Bulletin of the Geological Society of America, 84 (10), 3137-3180 (1973) doi:10.1130/00167606(1973)84<3137:PTATEO >2.0.CO;2

13. A.B. Ponomarev, V.V. Konyushkov, et al., Water and Ecology, 4 (24), 47-53 (2019) DOI: $10.23968 / 2305-3488.2019 .24 .4 .47-53$ 